\title{
Ríos Hernández, M. (Coord., 2011). Deportistas sin adjetivos. El deporte adaptado a las persones con discapacidad física. Madrid: Consejo Superior de Deportes.
}

El título de esta obra coral Deportistas sin adjetivos surgió. por lo que yo sé, de una conversación entre su coordinadora, Merche Ríos, y el propio Joan Palau, a quien va dedicada. Se trata de un titulo muy elocuente puesto que huye, tal como parece ser el deseo de ambos, del encasillamiento con el que era percibido, en su inicio, el deporte "específico" para personas con discapacidad. En efecto, dichas modalidades específicas del deporte tienen su sentido con determinados grupos de población, pero no dejan de ser prácticas más o menos alejadas del "deporte estándar". Por el contrario, el libro que reseñamos apuesta claramente por una visión de lo que podríamos definir como deporte para todas y todos. La principal intención del exhaustivo texto que comentamos consiste en apoyar el derecho que tenemos todas las personas al acceso a la práctica deportiva y a llevarla a cabo de un modo normalizado en las instalaciones deportivas de las que se dotan nuestras ciudades y pueblos. Una intención que, a mi entender, se alcanza con rigor y coherencia.

El libro se mueve en la dialéctica del acercamiento entre el deporte convencional y el deporte adaptado. Si bien tiene uno de sus capítulos dedicado a este último, su orientación principal gira alrededor de la práctica deportiva inclusiva en la que el deporte puede llevarse a cabo en contextos previstos para personas con y sin discapacidad, adoptando así la función socializadora que caracteriza la práctica deportiva en su máximo exponente. Se trata pues de una obra que asume el reto de articular unas propuestas avanzadas que sin duda podrán ser llevadas a la práctica, entre otras causas, gracias a trabajos como éste.

Si nos centramos en los contenidos del texto, lo primero que llama nuestra atención es la gran cantidad de autoras y autores que han participado en su elaboración. Conocer y haber colaborado con bastantes de ellos y con su coordinadora me permite apuntar dos hechos que pueden resultar de interés para quien se acerque a dicha obra:

En primer lugar, que la selección de las personas responsables de cada uno de los apartados no responde a una mera distribución de diferentes perspectivas sobre temáticas afines, como suele suceder en otras obras corales. En realidad se trata de especialistas en cada uno de los deportes que aborda el libro, que no sólo muestran un conocimiento detallado del deporte en cuestión, sino también su implicación 
personal y profesional en el desarrollo de las prácticas deportivas que analizan y describen. Me refiero aquí especialmente al extenso capítulo 2, que constituye el "cuerpo" del libro.

Pero en segundo lugar también puede resultar de interés constatar que el trabajo de coordinación llevado a cabo por Merche Ríos queda reflejado en la coherencia y continuidad claramente perceptibles entre las diferentes colaboraciones. Esto último nos permite recomendar dos tipos de lectura para un texto tan exhaustivo como el que comentamos.

El primero de ellos sería la lectura de consulta. En efecto, nos encontramos ante un libro de consulta de gran utilidad para técnicos y profesionales vinculados al deporte adaptado en el que pueden resolver rápidamente cualquier duda sobre la modalidad deportiva de su interés. En este sentido sería de gran utilidad que la institución responsable de su edición, el Consejo Superior de Deportes, y más concretamente al Real Patronato sobre Discapacidad y el Comité Paralímpico Español, promovieran una edición del texto en formato digital, sobre todo del contenido del capítulo 2. Las posibilidades del entorno digital ampliarían al máximo el impacto de esta obra y su accesibilidad desde diferentes ámbitos deportivos y formativos, pudiendo convertirse en una base de datos flexible y actualizada de la evolución del deporte adaptado, sus ampliaciones y sus normativas.

Ahora bien, volviendo a las recomendaciones para la lectura del texto, éste también permite, especialmente a quienes se acerquen a él con una intención directamente formativa (cursos INEF, cursos para profesorado de EF, formación de entrenadores, árbitros, monitores o técnicos de instalaciones deportivas, etc.) un segundo tipo de lectura más lineal de los capítulos primero y tercero, pues ambos abordan temas clave para entender, en su globalidad, la complejidad del deporte adaptado.

A continuación pasamos a exponer una breve relación de los contenidos del libro que puede orientar su lectura.

Luego de unos breves escritos introductorios, la obra empieza con un amplio capítulo dedicado a la evolución del deporte adaptado desde sus inicios hasta la actualidad. Perspectiva histórica que nos permite valorar el papel social que tienen hoy estas prácticas deportivas y sus principales retos. En este capítulo también se abordan, de una manera muy didáctica, importantes temas como la organización del deporte adaptado, las clasificaciones contempladas en su normativa, una valoración realista y ponderada de sus principales efectos entre la población con discapacidad, y termina con el análisis de algunos programas de desarrollo del deporte adaptado que hoy podemos considerar como referentes en nuestro país.

Con base en lo anterior, el segundo capítulo, el más extenso de la obra, proporciona una información completa, clara y armonizada de 18 modalidades deportivas adaptadas a las personas con discapacidad física, desde el atletismo al voleibol, pasando por la natación o la boccia (para citar también un deporte específico). Cada modalidad es presentada desde una visión muy actual, ilustrada gráficamente y con 
cuadros sinópticos que ayudan a la comprensión de las principales variables a tener en cuenta en la regulación de sus diferentes clases. A destacar el último apartado Otras modalidades deportivas que añade a las 18 presentadas un buen número de modalidades emergentes como el rugby o el balonmano en silla de ruedas.

La obra se cierra, en un obvio link con su primera parte, mediante un capítulo 3 dedicado a las perspectivas de futuro del deporte adaptado, en el que se abordan sus aspectos jurídicos, organizativos y de gestión, además de los vinculados con la gestión médica. Sin duda nos encontramos, y esto no es un formulismo, ante una obra imprescindible para todas y todos los profesionales que de un modo $u$ otro están vinculados al deporte adaptado, ya sea desde los ámbitos educativo, social, médico o técnico. Además, dicho libro también resulta muy recomendable a las y los profesionales de la comunicación, dado que aborda un ámbito emergente del deporte, con un creciente interés para los medios de comunicación.

Más allá de las consideraciones anteriores, permítanme terminar indicando que Deportistas sin adjetivos es también una destacable aportación al movimiento internacional para la inclusión social y educativa. A nadie se le oculta el valor de la práctica deportiva en los procesos de inclusión de los sectores más vulnerables de la población, entre los que se encuentran las personas con discapacidad. Y a ello no podemos ni queremos renunciar, aun siendo conscientes de la seria amenaza que sobre los logros alcanzados supone la actual crisis y las pulsiones regresivas que desgraciadamente suscita hacia situaciones de desigualdad que creíamos superadas.

Ignasi Puigdellívol. Dept Didàctica i Organització Educativa. Universitat de Barcelona 